\title{
A FORMAÇÃO DO TRABALHADOR E DA TRABALHADORA NUMA PERSPECTIVA FREIRIANA
}

\author{
Rodrigo de FreItAs AMORIM \\ Instituto Federal de Educação, Ciência e Tecnologia de Goiás (IFG), \\ Uruaçu, Goiás, Brasil
}

\begin{abstract}
Resumo: Através da pesquisa bibliográfica nos escritos de Freire procurou-se encontrar as categorias fundantes para uma reflexão crítica da formação profissional do trabalhador e da trabalhadora de modo a delinear o que seja um caminho libertador e emancipador para a formação destes na atualidade. A partir da categoria do ser sujeito, demonstra-se como o trabalhador e a trabalhadora constituem-se atores de sua história e criadores de seu mundo; nas categorias do tema-gerador, do diálogo, da educação como prática da liberdade, verifica-se que o sentido da expressão formação dos trabalhadores só pode ser compreendido em sua dimensão libertadora; e, nas categorias da participação, da militância e da educação como ato político, comprova-se que uma formação libertadora resulta na atuação consciente do trabalhador e trabalhadora sobre o mundo vivido para transformá-lo.
\end{abstract}

Palavras-chave: Trabalho. Educação. Formação libertadora. Perspectiva freiriana.

\section{INTRODUÇÃO}

O presente artigo tem como objetivo discutir a formação do trabalhador e da trabalhadora na atualidade através de categorias freireanas numa perspectiva libertadora e emancipatória. O legado de Freire, tanto de sua teoria, expressa em inúmeros escritos, quanto de sua prática, registrada 
em inúmeras experiências dentro e fora do país, suscita provocações para a reflexão do processo educativo brasileiro nos dias atuais.

Este texto toma essas provocações para refletir a formação do trabalhador e da trabalhadora, uma vez que esta se constitui uma necessidade e um desafio diante do mundo, da natureza e da sociedade: uma necessidade, porque da transformação da natureza e de seus recursos é que se organiza a própria sociedade; e um desafio, porque na complexa conjuntura do capitalismo atual, o trabalho sofre uma explícita exploração de sua força produtiva, exigindo trabalhadores e trabalhadoras subservientes dispostos a vender sua força de trabalho para obter sua sobrevivência, sem compreender o trabalho em sua dimensão criadora e transformadora da realidade social. Diante desta tensão entre o sobreviver e o criar, entre o vender sua força de trabalho alienadamente e inserir-se no mercado de trabalho de forma crítica, impõe-se a necessidade de pensar a formação do trabalhador e da trabalhadora numa perspectiva de superação da lógica exploratória do capital, possibilitando uma formação crítica e criadora que permita perspectivas de mudança para o sujeito, não só na busca de sua sobrevivência ou de melhorias de sua adaptação às condições do mercado de trabalho, mas, sobretudo na atividade criadora para organizar sua sociedade.

As perspectivas de Freire sobre a sociedade, o ser humano e o processo educativo podem contribuir para a compreensão da formação do trabalhador e da trabalhadora numa perspectiva libertadora e emancipatória. Sendo assim, questiona-se: que elementos do pensamento de Freire contribuem significativamente para pensar a formação do trabalhador e da trabalhadora que transcenda uma formação técnica, acrítica e aligeirada? Diante da complexidade das relações de trabalho da sociedade contemporânea marcada pela alta presença da tecnologia e do capital privado, como a perspectiva freireana pode contribuir para uma formação libertadora do trabalhador e da trabalhadora?

Através da pesquisa bibliográfica dos escritos de Freire tecer-se-á uma discussão sobre a formação destes sujeitos. Na primeira parte, "O trabalhador e a trabalhadora: sujeitos ou objetos?", discute-se a compreensão ontológica freireana do ser humano como ser inconcluso, inacabado, portanto, um "ser mais", que está destinado à construção de sua história como sujeito de suas ações criadoras e não como objeto. Na segunda parte, "A formação libertadora do trabalhador e da trabalhadora", procura-se demonstrar o sentido da palavra "formação", demonstrando-se que tomada num sentido mais amplo não pode ser confundida com o mero treinamento do trabalhadoreducando/trabalhadora-educanda para atuar no mercado de trabalho, pois que pressupõe a prática da liberdade, o uso do diálogo, a busca de temas 
geradores, que atuam juntos para a transformação do ser humano e do mundo ao seu redor. Na terceira parte, "A atuação do trabalhador e da trabalhadora na sociedade em que vivem", argumenta-se que quando há uma formação verdadeiramente libertadora, estes, conscientes de si e de sua realidade, tornam-se agentes de transformação de sua sociedade atuando sobre ela de forma ativa e coletiva, buscando solidariamente com seus companheiros e companheiras, construir caminhos para o estabelecimento do novo.

Como resultado final, este artigo provoca uma reflexão do sentido e da compreensão do trabalho, instigando críticas para o desvelamento das situações de exploração que usam o trabalho, no contexto atual, de forma alienada como meio de manutenção do status quo e das contradições de opressão na relação capital-trabalho.

O TRABALHADOR E A TRABALHADORA: SUJEITOS OU OBJETOS?

Freire foi um crítico voraz da educação brasileira, num sentido lato, não só relacionada às questões referentes à alfabetização de adultos, que para muitos o tornou conhecido pelo famoso método Paulo Freire', mas por pensar a educação em suas dimensões mais amplas buscando compreender sua relação com a sociedade e com o sentido ontológico do ser humano. Ele próprio afirma que, suas aspirações em relação à educação não eram apenas relativas à descoberta de uma técnica que auxiliasse na alfabetização das camadas populares de modo conscientizador e significativo, mas que tinha uma vontade "gulosa" de compreender os problemas da sociedade e da educação brasileira. Trabalho este iniciado em sua tese Educação e atualidade brasileira (1959), posteriormente, amadurecido em Educação como prática da liberdade (1965) e, consequentemente, selado na obra Pedagogia do oprimido (1967).

Nesta atitude "gulosa" de busca da compreensão dos problemas da educação brasileira, Freire colocou em destaque a indagação sobre a essência ontológica do ser humano, sua essência histórica, buscando nestes fundamentos da constituição da sua natureza e, consequentemente, da natureza social, a compreensão do mundo e das instituições criadas pela coletividade que produz o ser histórico, social e cultural. Foi indagando pela ontologia do ser humano que Freire afirmou que este é essencialmente um ser inacabado, um "estar sendo", um "ser mais". Comparando-se com os animais, a natureza histórica do ser humano o diferencia destes por possuir consciência de si e da própria natureza ao seu redor:

Na verdade, diferentemente dos outros animais, que são apenas inacabados, mas não são históricos, os homens se sabem inacabados. Têm consciência de sua inconclusão. Aí se encontram as raízes da educação mesma, como 
manifestação exclusivamente humana. Isto é, na inconclusão dos homens e na consciência que dela têm. Daí que seja a educação um quefazer permanente. Permanente, na razão da inconclusão dos homens e do devenir da realidade (FREIRE, 1987, p. 73).

É na compreensão desta inconclusão do ser humano que se deve também compreender a sociedade como historicamente construída e em constante construção, uma vez que ela é resultado de ações da coletividade, que organiza seu espaço, sua cultura, suas instituições sociais, seu trabalho e sua forma de vida. Não existe sociedade sem seres humanos e ela não pode subsistir sem que estes sejam problematizadores de sua própria realidade, sem que sejam sujeitos de suas vidas e histórias.

Diante desta concepção ontológica é que Freire tece algumas de suas mais severas críticas à educação brasileira tradicional, a qual ele denomina de "educação bancária" - por formar o educando-educanda para a passividade, para a domesticação, para a docilidade ingênua, que toma o ser humano como objeto negando-lhe sua condição ontológica de ser mais, de ser sujeito (FREIRE, 1980). Isso se evidencia na relação professor(a)-aluno(a), quando aqueles assumem a atitude de sujeitos que detêm o saber e tratam estes como objetos a serem preenchidos pelo saber alheio.

A narração, de que o educador é o sujeito, conduz os educandos à memorização mecânica do conteúdo narrado. Mais ainda, a narração os transforma em "vasilhas", em recipientes a serem "enchidos" pelo educador. Quanto mais vá "enchendo" os recipientes com seus "depósitos", tanto melhor educador será. Quanto mais se deixem docilmente "encher", tanto melhores educandos serão (FREIRE, 1987, p. 58).

Esta crítica à "educação bancária", consequentemente, ao modelo educativo que nega ao ser humano sua condição ontológica de ser "sujeito", é feita no contexto da contradição opressor-oprimido presente na sociedade, visto que esta é entendida em seus antagonismos, dividida por classes cujos interesses divergem entre a posse e domínio dos bens materiais e culturais. Freire (1987) afirma que a sociedade não é um tecido homogêneo, linear e sem contradições, pelo contrário, a sociedade é um tecido heterogêneo no qual subsistem aqueles que estão na posição de opressores - classes sociais que detêm o poder econômico e político - e, aqueles que estão na posição de oprimidos - classes sociais economicamente desfavorecidas que, geralmente, vendem sua força de trabalho para sua subsistência, consequentemente, perpetuando a manutenção da exploração do trabalho.

Portanto, aos opressores, o que lhes interessa é um modelo de educação que molde as demais classes sociais aos seus interesses de 
manutenção da ordem vigente, pois para eles esta ordem mantém sua condição de dominação e poder. A educação deve, assim, transmitir os conhecimentos, valores e comportamentos que tornem os demais subservientes ao estabelecido, como se a história fosse algo pronto e acabado, como se as diferenças de classes e de poder fossem naturais, próprias da essência da sociedade.

Trata-se de um modelo de "cultura do silêncio" que nega a sujeicidade do ser humano deixando-lhe a passividade, a alienação, a domesticação e a docilidade ${ }^{2}$. Assim, ao tornar o ser humano passivo, este modelo de educação serve aos interesses da classe dominante, transformando a mente do oprimido e não a sua situação de opressão.

Diante disso, Freire (2009) propõe uma educação como prática da liberdade, "ao contrário daquela que é prática da dominação, implica a negação do homem abstrato, isolado, solto, desligado do mundo, assim como também a negação do mundo como uma realidade ausente dos homens." (FREIRE, 1987, p. 70). Nesta educação libertadora o ser humano é tido em sua relação com o mundo como sujeito criador de suas relações e de sua história, como alguém capaz de construir, de pensar, de planejar seu futuro e trabalhar seu presente. Alguém que se relaciona dialeticamente com o mundo, de modo que a cada ação sua sobre este, o transforma, e ao transformá-lo é também por ele modificado, de modo a constituir-se um novo ser, em constante movimento de transformação, ao que Freire denominou de "estar sendo" (FREIRE, 1987). Sobre este ímpeto criador do ser humano, afirma:

Em todo homem existe um ímpeto criador. O ímpeto de criar nasce da inconclusão do homem. A educação é mais autêntica quanto mais desenvolve este ímpeto ontológico de criar. A educação deve ser desinibidora e não restritiva. É necessário darmos oportunidade para que os educandos sejam eles mesmos. (FREIRE, 1985, p. 17).

Diante destas perspectivas, Freire, especialmente em sua relação com adultos trabalhadores, deu importante ênfase à formação humana; uma formação conscientizadora e libertadora, que tivesse como ponto de partida o ser humano enquanto sujeito de seu mundo, e não objeto. O próprio método de alfabetização foi inicialmente pensado nesta perspectiva de valorização do ser humano e de suas experiências de vida, de modo que ele fosse ativo em todo o processo de alfabetização, considerando sua capacidade criadora e seus saberes prévios (FREIRE, 1980) ${ }^{3}$. Pensou-se numa alfabetização que fosse além de métodos mecânicos, com uma metodologia contextualizada e significativamente criadora de cultura, que explorasse a capacidade criadora e recriadora do ser humano, enquanto sujeito e não objeto. Um método que atingisse o sentido do aprender pelo homem. 
Por exemplo, numa das primeiras etapas do método era feito um diagnóstico da realidade da comunidade com quem se pretendia trabalhar para descobrir em sua cultura e modo de ver e compreender o mundo o seu universo vocabular. Deste universo vocabular eram escolhidas as palavrasgeradoras ${ }^{4}$ com as quais se daria o início da alfabetização dos adultos. Não se tratava de uma doação da palavra-geradora, pois primeiramente era trabalhado com os alfabetizandos o conceito de cultura, que por meio das "fichas de cultura" permitiam a estes a percepção crítica de que eram criadores de cultura, portanto, homens e mulheres sabedores, conhecedores de sua realidade, aprendizes e ensinadores. Iniciado este processo - aí sim conscientes de sua sujeicidade e de sua historicidade -, aos alfabetizandos eram apresentadas situações existenciais de sua realidade por meio de figuras codificadas que problematizavam esta realidade. Os alfabetizandos, por meio da descodificação e leitura das fichas de leitura apreendiam as palavras de uma forma significativamente revolucionária, o que pressupõe a atividade criadora dos seres humanos como sujeitos da aprendizagem e a apreensão da linguagem escrita por meio da criação interna do código linguístico (FREIRE, 1987).

Esta forma de organizar o método de alfabetização, que não se reduzia a uma técnica, estava insuflada de uma concepção libertadora dos seres humanos como sujeitos. Tal fato se evidenciou na própria nomenclatura que fora dada aos atores participantes do processo de alfabetização, como observa Beisiegel (2010, p. 42, grifo do autor):

Por isso mesmo, já a nomenclatura que adotava no método de alfabetização exprimia a intenção de alterar radicalmente as práticas então usuais na educação do adulto analfabeto. As "classes" eram substituídas pelos "círculos de cultura", os "alunos" pelos "participantes dos grupos de discussões", os "professores" cediam lugar aos "coordenadores de debates". De igual modo, a "aula" era substituída pelo "debate" ou pelo "diálogo" entre educador e educandos e o "programa" por "situações existenciais" capazes de desafiar os agrupamentos e de levá-los a assumir posições de reflexão e crítica diante das condições dessa mesma existência.

Foram estas condições preconizadas e praticadas pelo método de alfabetização - para além de uma postura meramente metodológica -, uma compreensão epistemológica do conhecimento somada à compreensão ontológica do ser humano como ser mais - ser sujeito -, que permitiu o êxito dos círculos de cultura criados inicialmente no nordeste e, posteriormente, em várias localidades do Brasil afora 5 .

Diante desta perspectiva, a formação do trabalhador e da trabalhadora passa a ser pensada e praticada a partir da categoria ontológica 
do ser humano enquanto sujeito. Não se trata apenas do sujeito humano em sua dimensão ética ou moral, mas em sua totalidade, sujeito transformador de seu mundo e de si próprio, sujeito criador de cultura, capaz de organizar e decidir com seus pares os rumos de sua vida e de sua história.

Portanto, ao tomar a concepção de sujeito deve-se, consequentemente, negar sua reificação como objeto, ao qual apenas se Ihe transfere conhecimentos técnicos para execução de atividades necessárias à expansão do capital por meio do comércio de tecnologias cada vez mais incrementadas; pois como objeto, o que interessa a quem promove a formação de mão de obra para atender às demandas do mercado, não é que o trabalhador e a trabalhadora tenham consciência de seu trabalho como atividade criadora e transformadora da realidade, mas que somente atuem transformando a natureza em benefício da manutenção da ordem vigente. Sua recompensa é o estar empregado e receber seu salário, ao que deverá manifestar sua gratidão porque outros estão desempregados e sem salários.

Isso significa que assumir o trabalhador e a trabalhadora como sujeitos, implica também, assumir uma nova compreensão da realidade social, como historicamente determinada por condicionamentos sociais, econômicos e políticos; assumir a possibilidade da mudança e do questionamento das estruturas vigentes e, as desigualdades sociais como uma contradição presente na sociedade do capital.

\section{A FORMAÇÃO LIBERTADORA DO TRABALHADOR E DA TRABALHADORA}

É importante frisar que a obra de Freire não se restringiu ao processo de alfabetização de adultos, mas também deu atenção especial ao processo de pós-alfabetização, que deveria dar continuidade aos trabalhos de aquisição da linguagem escrita. Tanto a alfabetização quanto a pós-alfabetização foram pensadas a partir de "palavras" $\mathrm{e}$ "temas" geradores, respectivamente, ou seja, é a partir do universo vocabular dos educandos, de sua realidade histórica e cultural, dos temas vivenciados no cotidiano que se relacionam com seus "saberes de experiência feitos" (FREIRE, 1987), por meio do diálogo entre as pessoas, educadores/educadoras-educandos/educandas, que se promoverá uma formação libertadora e emancipadora.

A esta premissa se impõe questões primazes para a reflexão da formação do trabalhador e da trabalhadora na atualidade: qual o lugar de sua realidade histórica e cultural e seus "saberes de experiência feitos" nas políticas de formação profissional? Como é possível uma formação libertadora do trabalhador e da trabalhadora, se, historicamente, os programas já vêm prontos, de cima para baixo, para atender à formação de mão de obra para o mercado de trabalho? 
O que se depreende destes questionamentos é a necessidade de desvelar o sentido da palavra "formação" presente nos programas profissionalizantes. Pois, se a formação do trabalhador é pensada, organizada e implementada, tendo em vista um corpo técnico de especialistas que a organizam para ser, depois, transferida para as localidades espalhadas pelo solo brasileiro, então, que tipo de formação está subjacente a esta prática? Certamente, não se trata da formação em seu sentido mais amplo, como formação humanizadora, problematizadora e libertadora, mas de "(de) formação", pois está a cargo apenas das necessidades de perpetuação das estruturas vigentes de exploração do trabalho e manutenção da contradição opressor-oprimido.

Nesse sentido, em uma abordagem freireana, para pensar a formação do trabalhador e da trabalhadora é necessário fazer o questionamento sobre o sentido dado à própria formação. Formar para quem e contra quem? Se esta formação é para atender às demandas de mão de obra do mercado, então, é uma formação para o capitalista (para quem) e contra o próprio trabalhador e trabalhadora enquanto sujeitos históricos e sociais (contra quem). Assim, estes sujeitos estariam se"(de)formando" contra si próprios, apreendendo técnicas, habilidades e competências que negam sua própria realidade e que somente perpetuam sua relação de submissão à exploração do mercado. Não se pode, nesse contexto, e com o uso desse sentido da palavra formação, utilizá-la, pois o que se tem é o treinamento, o adestramento e não a formação. Não pode haver formação na qual o que impera é a transmissão de conhecimentos "de A para B ou de A sobre B" (FREIRE, 1987). Este é o modelo da educação bancária, inautêntica, desumanizadora e antidialógica, que "é o treino técnicocientífico do educando e não sua formação de que já não se fala. Formação que, incluindo a preparação técnico-científica, vai mais além dela." (FREIRE, 1998, p. 142)

Contrapondo-se ao modelo da educação bancária e compreendido o sentido mais amplo da palavra formação, Freire propõe que a formação do trabalhador e da trabalhadora seja pensada e praticada na perspectiva da educação popular ${ }^{6}$, uma educação democratizadora e progressista que vê nestes sujeitos agentes fundantes dos processos democráticos, pois que é pelo trabalho que se cria e recria, se organiza e reorganiza, se transforma a própria sociedade. Neste sentido, Freire (2011, p. 183) afirma:

Numa perspectiva progressista, a educação popular não pode, por outro lado, reduzir-se ao puro treinamento técnico de que grupos de trabalhadores realmente precisam. Esta é a maneira necessariamente estreita de formar, que à classe dominante interessa, a que reproduz a classe trabalhadora como 
tal. Na perspectiva progressista, naturalmente, a formação técnica é também uma prioridade, mas, a seu lado, há outra prioridade que não pode ser posta à margem. O operário que está aprendendo, por exemplo, o ofício de torneiro, de mecânico, de pedreiro, de marceneiro, tem o direito e a necessidade de aprendê-lo tão melhor quanto possível, mas tem, igualmente, o direito de saber a razão de ser do próprio procedimento técnico. Tem o direito de conhecer as origens históricas da tecnologia, assim como o de tomá-la como objeto de sua curiosidade e refletir sobre o indiscutível avanço que ela implica, mas, também, sobre os riscos a que nos expõe [...] (grifo do autor).

Desta forma, há que se pensar na formação do trabalhador e da trabalhadora como uma formação mais ampla - problematizadora - que leve em consideração os conhecimentos técnicos necessários à prática profissional e sua contextualização histórico-social, e que oportunize a estes o desenvolvimento de suas habilidades garantindo-lhes o direito de reconhecer nas origens de tais técnicas seus benefícios e riscos, bem como seus condicionamentos históricos, sociológicos e ideológicos, que desvelam a realidade em sua totalidade com suas ambiguidades e contradições. Trata-se de reconhecer o aspecto político e ideológico da educação, desde a concepção dos conteúdos à avaliação do processo educativo.

Desta forma, a formação do trabalhador e da trabalhadora só poderá ser libertadora se construída a partir do diálogo, categoria fundamental para o exercício da liberdade e da humanização do ser humano. “O diálogo é este encontro dos homens, mediatizados pelo mundo, para pronunciá-lo, não se esgotando, portanto, na relação eu-tu" (FREIRE, 1987, p. 78, grifo do autor), mas estendendo-se ao mundo transformando-o e, consequentemente, modificando a relação entre os próprios seres humanos. Só haverá formação libertadora se esta se constituir por meio do diálogo entre os agentes constitutivos da formação profissional, entre instituições de ensino e a comunidade, entre educadores/educadoras e educandos/educandas.

O diálogo exige dos que dele participam uma visão autêntica do ser humano por meio de relações permeadas em atitudes como o amor, a humildade, a fé nos homens, a confiança mútua, a esperança, o pensar verdadeiro e crítico que não dicotomiza a realidade em sua totalidade, criando falsamente a separação entre ser humano-mundo (FREIRE, 1987).

Esta permanente atitude de diálogo deve ser a base para a "busca do conteúdo programático" (FREIRE, 1987, p. 83). Quando se diz busca, não se quer dizer que os conteúdos técnico-científicos devam ser esquecidos e deixados de lado para que novos conteúdos a partir dos conhecimentos populares sejam eleitos para o processo pedagógico. $O$ que se intenta é que o educador/educadora não deve chegar ao educando/educanda como quem 
tem, simplesmente, um programa em mãos para ser cumprido e, que, portanto, será despejado expositivamente sobre as cabeças dos educandos. Isso seria uma "invasão cultural" (FREIRE, 1982), pois que os conhecimentos prévios, ainda que regados pelo senso comum dos educandos, lhe seriam negados como realidade cultural própria. Então, o novo conhecimento, vindo de um programa, não seria para estes senão que uma invasão de sua cultura acusandoIhes continuamente que sua forma de pensar e ver o mundo estão erradas. ${ }^{7}$

Esta atitude de invasão cultural, própria da educação bancária, deve ser superada pela educação libertadora que vê no diálogo o início de qualquer processo formativo, seja ele incipiente como na alfabetização, seja ele técnico como na formação profissional. Por meio desse diálogo é possível compreender a visão de mundo dos trabalhadores e trabalhadoras, sua realidade em situação, seus condicionamentos e, assim, dialogando com eles, decidir pelo conteúdo programático que será relevante e significativo, efetivamente formador e não apenas treinamento adestrador.

Frise-se que não se trata de uma negativa dos conhecimentos técnico-científicos necessários à prática das profissões, mas de respeitar o trabalhador e a trabalhadora como sujeitos que possuem situações históricas específicas, com sua linguagem e significados, e que, portanto, precisam ser respeitados nisso, para que tenham interesse real e efetivo num conhecimento técnico-científico que não será a supressão de seus conhecimentos, mas a conquista de novos para transformação de sua realidade.

A partir do diálogo, a formação libertadora do trabalhador e da trabalhadora, antes de se preocupar com o conjunto de conhecimentos técnico-científicos, se preocupará com a compreensão da realidade vivida do trabalhador, sua visão de mundo, seu "pensamento-linguagem", suas "situações-limite", para encontrar o que Freire denominou de "temas geradores".

Estes temas se chamam geradores porque, qualquer que seja a natureza de sua compreensão, como a ação por eles provocada, contêm em si a possibilidade de desdobrar-se em outros tantos temas que, por sua vez, provocam novas tarefas que devem ser cumpridas (FREIRE, 1987, p. 93).

Em que pese a importância dos conhecimentos técnico-científicos, a identificação dos"temas geradores" relacionados à formação de trabalhadores e trabalhadoras, constitui-se como reconhecimento da sua realidade histórica, da importância de sua visão de mundo, de sua linguagem, de seu pensamento, como elementos essenciais para, a partir deles, iniciar o processo de formação profissional que supere o mero treinamento de mão de obra. Pois, 
Não importa em que sociedade estejamos, em que mundo nos encontremos, não é possível formar engenheiros ou pedreiros, físicos ou enfermeiras, dentistas ou torneiros, educadores ou mecânicos, agricultores ou filósofos, pecuaristas ou biólogos sem uma compreensão de nós mesmos enquanto seres históricos, políticos, sociais e culturais, sem uma compreensão de como a sociedade funciona. E isto o treinamento supostamente apenas técnico não dá (FREIRE, 2011, p. 186, grifo do autor).

Nessa perspectiva freireana, a formação libertadora do trabalhador e da trabalhadora implica, portanto, a superação do treinamento por meio da transmissão de conhecimentos técnico-científicos. Implica a consideração do ser humano e de sua realidade histórica como fatores que não podem ser desprezados, sem que se sacrifique a liberdade, a democracia e a emancipação do trabalhador/trabalhadora. Uma nova maneira de lidar com os programas e com os conteúdos profissionais e tecnológicos se impõe como desafio aos educadores/educadoras e às instituições de educação profissional e tecnológica, isto é, de pensar suas próprias significações e a serviço do que, de quem, contra o que, contra quem estão atuando.

Se se trata o trabalhador e a trabalhadora como algo mais que "mão de obra" para atender ao mercado de trabalho e lhes considere em sua dimensão ontológica de sujeitos e seres mais, então, se deve pensar na formação, e não no mero treinamento, que auxilie o trabalhador e a trabalhadora a alcançarem sua liberdade, que não significa sobrepor-se aos demais, em riqueza, saber ou poder, mas reconhecer-se com os demais, na construção da riqueza, do poder e dos saberes, que devem ser compartilhados de forma justa e igualitária entre todos.

A ATUAÇÃO DO TRABALHADOR E DA TRABALHADORA NA SOCIEDADE EM QUE VIVEM

Em decorrência de uma formação libertadora do trabalhador e da trabalhadora, tem-se o desvelamento das relações históricas de opressão e exploração, o desvelamento feito pelo trabalhador/trabalhadora como sujeito histórico capaz de agir em coletividade pela transformação de sua sociedade. Este desvelamento da dimensão política da práxis educativa quanto da práxis profissional revela aos trabalhadores e às trabalhadoras a importância de sua atuação social na sociedade. Isso significa rejeitar as explicações ideológicas da realidade ${ }^{8}$ que procuram tornar o mundo metafísico, supranatural, como se as coisas fossem naturalmente como são, estáticas e alheias às mudanças.

À formação libertadora do trabalhador e da trabalhadora deve se seguir sua atuação no mundo, uma vez que o ser humano é um ser no mundo e com o mundo, transformando-o e, assim, construindo sua cultura, sua história, 
seu novo mundo, sem o qual não existiria nem o ser humano, ser pensante, nem o mundo além de seu mero suporte (FREIRE, 1995), igualando-se assim ao animal que vive no suporte e não é capaz de, pois não tem consciência de si nem do mundo, transformá-lo em cultura e história

No processo de alfabetização e pós-alfabetização do povo de São Tomé e Príncipe, assessorado por Freire nos anos de 1970, percebese esta preocupação de atuação na sociedade em que se vive por meio da reconstrução nacional do país que passava por um processo de independência ${ }^{10}$. Freire enfatizava a indissociabilidade do ato educativo e do ato político de reconstrução nacional, desta forma, a cultura popular e sua visão de mundo eram consideradas como ponto de partida para o processo educativo e, o trabalho, como elemento básico transformador do mundo e criador da cultura, era problematizado nos cadernos de leitura do processo pedagógico, desvelando-se as mistificações em torno dele como a dicotomização entre trabalho manual versus trabalho intelectual - e apontando para seu exercício em sua totalidade (FREIRE, 1989). A título de exemplo, segue abaixo um dos textos presentes nos cadernos de pósalfabetização, intitulado "Trabalho e transformação do mundo", que introduzia o tema do trabalho no processo educativo:

Pedro e Antônio derrubaram uma árvore. Tiveram uma prática. A atividade prática dos seres humanos tem finalidades. Eles sabiam o que queriam fazer ao derrubar a árvore. Trabalharam. Com instrumento, não só derrubaram a árvore mas a desbastaram, depois de derrubá-la, dividiram o grande tronco em pedaços ou toros, que secaram ao sol. Em seguida, Pedro e Antônio serraram os troncos e fizeram tábuas com eles. Com as tábuas, fizeram um barco. Antes de fazer o barco, antes mesmo de derrubarem a árvore, eles já tinham na cabeça a forma do barco que iam fazer. Eles já sabiam para que iam fazer o barco. Pedro e Antônio trabalharam. Transformaram com o seu trabalho a árvore e fizeram com ela um barco. É trabalhando que os homens e as mulheres transformam o mundo e, transformando o mundo, se transformam também (FREIRE, 1989, p. 72-73, grifo nosso).

Há dois personagens em sua situação vivencial concreta que atuam sobre o seu suporte (árvore) com a intenção (consciência de si e do seu suporte) de transformá-lo, por meio do trabalho, e construir seu mundo (tábuas » barco), que já não é mais suporte, mas um novo mundo, isto é, transformaram com o seu trabalho o suporte existencial e fizeram com ele um mundo de cultura, criaram história e, o resultado disso é que se transformam também ${ }^{11}$. Este ato transformador por meio do trabalho implica um processo de formação educativa e pedagógica que compreenda a educação na sua dimensão emancipadora e, portanto, como intencionalmente voltada para instigar no ser humano a sua atividade criadora. 
Percebe-se que há uma nítida vinculação do processo de formação educativa do povo com a concepção deste como trabalhador, ou seja, não se dicotomiza a realidade nem a relação ser humano-mundo, ao contrário, se desvela a totalidade da realidade demonstrando que este não pode estar separado de sua realidade nem do seu trabalho como se ambos existissem independentemente um do outro. Há, portanto, neste caso em particular, como exemplo experiencial vivido, bem como em toda a construção teórica freireana, uma nítida ênfase na atuação do ser humano como sujeito transformador de sua sociedade. Aplicando-se este raciocínio ao campo de formação do trabalhador e da trabalhadora, pode-se afirmar que a formação libertadora destes deve, peremptoriamente, desaguar numa atuação construtiva dos mesmos sobre a sociedade em que vivem. Em termos práticos isso significa agir sobre as estruturas existentes transformando-as coerentemente com a vocação ontológica do "ser mais", isto é, denunciar as práticas desumanizadoras e exploratórias do ser humano e de seu trabalho e anunciar práticas humanizadoras e solidárias, em que tanto o trabalho como seu produto sejam compartilhados solidariamente na constituição de uma sociedade justa.

Nesse sentido, é importante frisar, dentro de uma compreensão dialética, que toda formação educativa promove a atuação do/da educando/ educanda sobre a sociedade em que vive. Mesmo na concepção bancária, em que se "(de)forma" para a ingenuidade, para a passividade, negando ao ser humano sua condição de sujeito, coisificando-o como simples objeto, este está atuando sobre a sociedade em que vive, atuando de forma passiva, reacionária, não inquisidora, atuando a favor da manutenção do status quo que só interessa àqueles que estão numa posição de dominação. Neste aspecto, percebe-se que não pode haver uma neutralidade da educação e nem do posicionamento que o ser humano assume ante seu suporte existencial e seu mundo. O simples fato de tencionar, permanecer neutro significa, por si só, um posicionar-se a favor da permanência das coisas e, portanto, da manutenção da realidade da contradição opressor-oprimido. O problema é que, muitos, em nome desta suposta neutralidade, não têm consciência da não neutralidade de sua posição, por isso, um dos aspectos freireanos da educação é a conscientização para a liberdade, é o desvelamento da realidade concreta, que desvelando também a condição de sujeito capaz de atuar sobre o mundo em que vive, passa a acreditar na possibilidade da transformação e enxergá-la como possível porque feita por mãos humanas.

Esta atuação não pode ser isolada nem individualista, pois que sozinhos os seres humanos sequer podem se reconhecer humanos. Sozinhos cooperam para a manutenção da situação de opressão, para a qual, o individualismo se manifesta como matriz de sustentação. Em contrapartida, 
a comunhão se torna fundamento da solidariedade que permite aos seres humanos a comunicação de seus problemas e organização de sua atuação para a busca de soluções.

Trata-se de uma comunhão solidária em torno de objetivos compartilhados, da participação, do trabalho em equipe, da militância e mobilização na busca de soluções para os problemas reais experimentados pelos seres humanos em sociedade, uma vez que o trabalhador e a trabalhadora, ainda que em processo de formação, não se distanciam de seus problemas para, isolados do mundo e da realidade, estudar técnicas profissionais, e depois, "cheios" destas técnicas, voltarem à realidade. Enquanto se forma profissionalmente, vivência seus problemas diariamente. Se a formação pouco se relaciona com sua realidade, tampouco efeito terá sobre o enfrentamento de seus problemas e a busca de soluções, mas, se é uma formação libertadora, então, jamais prescinde da realidade concreta, ao contrário, parte desta problematizando-a para que o aprendizado técnico e profissional resulte em atuação significativa sobre a sociedade ${ }^{12}$.

\section{CONSIDERAÇÕES FINAIS}

Pensar a formação do trabalhador e da trabalhadora numa perspectiva freireana é um desafio que se impõe para além do planejamento de conteúdos técnicos e profissionalizantes, de metodologias e didáticas de aplicação mais eficazes, e de questões relativas às habilidades e competências para inserção no mercado de trabalho. É um desafio para pensar a própria essência do ser humano enquanto trabalhador e trabalhadora, seu ser sujeito e seu poder criador sobre o mundo; pensar o sentido mais amplo do que significa a palavra "formação", compreendendo-a na superação do simples treinamento e que a vê como prática da liberdade, uma vez que não pode haver formação sem que se considere o trabalhador e a trabalhadora como sujeitos de sua história. Por conseguinte, é o desafio de pensar a formação do trabalhador como algo político e não simplesmente burocrático. Político porque entende que os resultados desta formação libertadora possuem relação direta com as condições de vida e os rumos da sociedade, e não burocrático, porque não se pode falar em qualidade de formação do trabalhador/trabalhadora pelo simples fato de se possuir um histórico escolar com boas notas, baixos índices de evasão e certificação, tais elementos sem se traduzirem em atuação transformadora do mundo e da sociedade nada passam de burocracia que reafirmam a permanência das contradições de dominação e exploração do capital sobre o trabalho.

Numa perspectiva freireana, é possível pensar a formação libertadora do trabalhador e da trabalhadora. Visualizar, por meio dela, e da atuação 
destes sujeitos, consciente de si, do outro e do mundo que compartilham com seus pares, uma sociedade melhor, que pode ser pensada e refletida como possível de ser modificada e transformada, passando a ser parte integrante da totalidade da existência dos trabalhadores e trabalhadoras, os quais não se veem mais distanciados, mas integrados a ela. Assim, é possível cultivar a esperança e o sonho, de no presente, por meio do trabalho consciente e o estabelecimento de novas relações sociais entre os seus atores, questionar o poder dos opressores e dominadores, mobilizando forças e ações para transformar as estruturas de dominação e construir o novo, no qual a contradição opressor-oprimido não seja mais o fator determinante da vida em sociedade, mas novas contradições que façam da liberdade, do humanismo ético, da solidariedade e da democracia, os fatores determinantes dessa outra realidade possível.

Enfim, a perspectiva freireana da formação libertadora do trabalhador e da trabalhadora resgata a compreensão do sentido do trabalho como ato criador e transformador do mundo, desvelando os sentidos ideológicos que reduzem o trabalho, sob a égide do capitalismo atual, ao emprego e às atividades meramente ligadas à subsistência. Possibilita uma formação para a desalienação, constituindo-se, desta forma, como revolucionária, pois abre portas para o sonho possível da transformação.

\section{THE WORKER FORMATION IN THE FREIREAN PERSPECTIVE}

AвSTRACT: Through the bibliographical research in the writings of Freire, we sought to find the founding categories for a critical reflection of the professional formation of the worker in order to delineate what is a liberating and emancipatory way for the formation of them in the present time. From the category of being subject, it is demonstrated how the workers constitute themselves actors of their history and creators of their world. In the categories of theme generator, of dialogue, of education as a practice of freedom, it is verified that the meaning of the expression formation of workers can only be understood in its liberating dimension. And in the categories of participation, militancy and education as a political act, it is proved that a liberating formation results in the conscious action of the worker on the world lived in order to transform it.

KEYWORDS: Work. Education. Liberating formation. Freirean perspective. 


\section{LA FORMACIÓN DE LOS TRABAJADORES EN LA PERSPECTIVA DE FREIRE}

RESUMEN: A través de investigación bibliográfica en los escritos de Freire se procuró encontrar las categorías fundadoras para una reflexión crítica de la formación profesional del trabajador y de la trabajadora para delinear qué es un camino libertador y emancipador para la formación de ellos/as en la actualidad. A partir de la categoría del ser sujeto, se demuestra cómo el trabajador y la trabajadora se constituyen en actores de su historia y en creadores de su mundo; en las categorías del tema-generador, del diálogo, de la educación como práctica de la libertad, se verifica que el sentido de la expresión formación de los trabajadores sólo puede ser comprendido en su dimensión libertadora; y, en las categorías de participación, de la militancia y de la educación como un acto político, se comprueba que una formación libertadora resulta en la acción consciente del trabajador y de la trabajadora sobre el mundo vivido para transformarlo.

Palabras Clave: Trabajo. Educación. Formación libertadora. Perspectiva freireana.

\section{NOTAS}

1 Beisiegel afirma que há equívocos na compreensão das concepções de Freire, mesmo dentro da comunidade universitária, devido sua associação com o processo de alfabetização de adultos no final dos anos de 1950 e início de 1960 e, posteriormente, o exílio em 1964 por meio do Golpe Militar, teria cooperado para estas distorções em sua imagem reduzindo-o ao "criador de uma nova técnica de alfabetização" (2008, p. 35).

2 Freire elenca inúmeras ações do educador em relação ao educando que confirmam esta postura da educação bancária: "a) o educador é o que educa; os educandos, os que são educados; b) o educador é o que sabe; os educandos, os que não sabem; c) o educador é o que pensa; os educandos, os pensados; d) o educador é o que diz a palavra; os educandos, os que a escutam docilmente; e) o educador é o que disciplina; os educandos, os disciplinados; f) o educador é o que opta e prescreve sua opção; os educandos, os que seguem a prescrição; g) o educador é o que atua; os educandos, os que têm a ilusão de que atuam, na atuação do educador; h) o educador escolhe o conteúdo programático; os educandos, jamais ouvidos nesta escolha, se acomodam a ele; i) o educador identifica a autoridade do saber com sua autoridade funcional, que opõe antagonicamente à liberdade dos educandos; estes devem adaptar-se às determinações daquele; j) o educador, finalmente, é o sujeito do processo; os educandos, meros objetos." (1987, p. 59).

3 Freire e sua equipe criticavam o método de alfabetização baseado nos abecedários da época, pois não se relacionavam com o mundo do trabalhador e "que pretendem oferecer a montagem dos signos gráficos, reduzindo o analfabeto ao estado de objeto e não de sujeito de sua própria alfabetização." (FREIRE, 1980, p. 41). 
4 As palavras geradoras eram escolhidas mediante o atendimento de dois critérios básicos: possuir riqueza fonêmica e estar contextualmente relacionada à realidade local do alfabetizando (BEISIEGEL, 2008).

5 Em 1962, na experiência de alfabetização de Angicos, registra-se que 300 trabaIhadores foram alfabetizados em 45 dias de trabalho. Com o sucesso do método de alfabetização de adultos e sua repercussão regional e nacional, "entre junho de 1963 e março de 1964, desenvolveram-se cursos de capacitação de coordenadores em quase todas as capitais dos estados [...]. O plano de 1964 previa a instalação de 20.000 círculos que já se encontravam capacitados para atender, durante este ano, a aproximadamente 2 milhões de alfabetizados [...]" (WEFFORT, 2009, p. 19). Plano este que foi malogrado pelo Golpe Militar em abril de 1964.

6 Há duas concepções básicas de "educação popular": a primeira, cunhada nos documentos oficiais deste a instauração da obrigatoriedade de oferta e frequência da escola pública pelas leis e regulamentos parlamentares, que compreende a educação popular como um direito fundamental do povo que deve ser garantido pelo Estado e, portanto, trata-se de uma espécie de doação ou concessão do Estado para o povo; a segunda, ligada aos movimentos sociais e preconizada pela pedagogia libertadora que compreende a educação popular como uma educação do e com o povo, em que seus conteúdos e métodos são construídos a partir da realidade histórica e social da sociedade (BEISIEGEL, 2008). Mais sobre o conceito de educação popular (vide BARREIRO, 2000).

7 No livro Extensão ou comunicação?, Freire aborda a questão do agrônomo-educador no Chile, que tinha como atividades extensionistas a capacitação de camponeses das zonas rurais por meio de conhecimentos técnico-científicos para lidar com problemas práticos relacionados à erosão do solo, à agricultura, ao tratamento de pestes, dentre outros. Freire afirma que a palavra "extensão", apesar de usada com a intenção positiva de levar conhecimentos científicos necessários àquelas comunidades, possui um "equívoco gnosiológico", pois o que de fato se fazia era a transmissão de conhecimentos de forma bancária, afirmando as relações de poder em que o agrônomo-educador é quem sabe e os camponeses nada sabem. A esse movimento, ainda que intencionalmente positivo, mas não menos domesticador e impositivo, é que Freire denominou de "invasão cultural". Como alternativa libertadora para este processo, o autor propôs a "comunicação", sinônima do diálogo, capaz, portanto, de levar o agrônomo-educador ao interesse de compreender os conhecimentos dos camponeses e suas práticas, para depois, em diálogo com eles, e a partir da realidade deles, compartilhar seus conhecimentos técnico-científicos (FREIRE, 1982).

8 "O discurso ideológico nos ameaça de anestesiar a mente, de confundir a curiosidade, de distorcer a percepção dos fatos, das coisas, dos acontecimentos. Não podemos escutar, sem um mínimo de reação crítica, discursos como estes: 'O negro é geneticamente inferior aos brancos. É uma pena, mas é isso o que a ciência nos diz.' ‘Em defesa de sua honra, o marido matou a mulher.'Que poderíamos esperar deles, uns baderneiros, invasores de terra?"Essa gente é sempre assim: damos-Ihe os pés e 
logo quer as mãos.'Nós já sabemos o que o povo quer e do que precisa. Perguntar-Ihe seria uma perda de tempo.' $O$ saber eruptivo a ser entregue às massas incultas é a sua salvação."' (FREIRE, 1998, p. 149-150).

90 suporte se refere às condições materiais que garantem a existência física e material das coisas e dos seres. O mundo é o resultado da ação consciente do ser humano sobre seu suporte existencial transformando-o em mundo, cultura e história. Freire, o animal está limitado ao seu suporte e nada pode fazer além dele, pois que está instintivamente programado para viver nesta condição. O ser humano, por sua vez, devido sua capacidade criadora e transformadora da realidade, transforma o suporte em mundo, e assim, torna-se essencialmente diferente dos animais (FREIRE, 1995).

10 Em seu período de exílio (1964-1980) Freire viveu parte de sua vida em Genebra, Suíça, como diretor do Departamento de Educação do Conselho Mundial de Igrejas, de onde exerceu inúmeras atividades de assessoria em educação a governos de países da África em processo de descolonização e independência. Em Pedagogia da esperança: um reencontro com a pedagogia do oprimido, narra diversas destas histórias (FREIRE, 2011). Sobre o caso de São Tomé e Príncipe, o livro A importância do ato de ler: em três artigos que se completam, no terceiro artigo mais especificamente, Freire narra o processo de alfabetização e pós-alfabetização realizado naquele país sob sua assessoria e apresenta os cadernos de leitura elaborados e utilizados para aquele processo educativo (FREIRE, 1989).

11 O barco representa uma tecnologia que pode possibilitar a modernização e o desenvolvimento daquela sociedade, porém, é importante observar que nem toda modernização significa desenvolvimento, especialmente se for resultado de um ato mecanicista e/ou tecnicista (FREIRE, 1982).

12 Em Cartas à Guiné-Bissau, Freire escreve a um país em processo de descolonização e reconstrução nacional. Na carta de $n^{\circ} 5$ endereçada à Comissão de Alfabetização do país com cópias para outros militantes envolvidos, destaca a importância de todo o processo educativo, tanto da alfabetização quanto da pós-alfabetização, ser encaminhado coerentemente com as práticas produtivas do povo, de modo que todo o processo pedagógico se constituísse como um processo pedagógico do espaço escolar e do espaço produtivo. Nesta carta, ele enfatiza ainda a importância da "participação criticamente consciente do povo no empenho da reconstrução nacional e no da criação de uma nova sociedade. Participação sem a qual dificilmente se reconstruirá o país e mais dificilmente ainda se criará a nova sociedade." (FREIRE, 1984, p. 156).

\section{REFERÊNCIAS}

BARREIRO, Júlio. Educação popular e conscientização. Tradução Carlos Rodrigues Brandão. Porto Alegre: Sulina, 2000.

BEISIEGEL, Celso de Rui. Freire. Recife: Fundação Joaquim Nabuco, Editora Massangana, 2010. 
. Política e educação popular: a teoria e a prática de Freire no Brasil. 4. ed. Brasília: Liber Livro, 2008.

FREIRE, Paulo. Conscientização: teoria e prática da libertação. Uma introdução ao pensamento de Freire. Tradução Kátia de Mello e Silva. 3. ed. São Paulo: Editora Moraes, 1980.

. Extensão ou comunicação? Tradução Rosisca Darcy de Oliveira. 6. ed. Rio de Janeiro: Paz e Terra, 1982.

. Cartas à Guiné-Bissau: registros de uma experiência em processo. 4. ed. Rio de Janeiro: Paz e Terra, 1984.

. Educação e mudança. 10. ed. Rio de Janeiro: Paz e Terra, 1985.

. Pedagogia do oprimido. 17. ed. Rio de Janeiro: Paz e Terra, 1987.

. A importância do ato de ler: em três artigos que se completam. 23. ed. São Paulo: Autores Associados, Cortez, 1989.

. À sombra desta mangueira. São Paulo: Olho d'água, 1995.

. Pedagogia da autonomia: saberes necessários à prática educativa. 9. ed. Rio de Janeiro: Paz e Terra, 1998.

. Educação como prática da liberdade. Rio de Janeiro: Paz e Terra, 2009.

. Pedagogia da esperança: um reencontro com a pedagogia do oprimido. Rio de Janeiro: Paz e Terra, 2011.

WEFFORT, Francisco C. Educação e política: reflexões sociológicas sobre uma pedagogia da Liberdade. In: FREIRE, Paulo. Educação como prática da liberdade. 32. reimpr. Rio de Janeiro: Paz e Terra, 2009. p. 9-36.

Rodrigo de Freitas Amorim: Bacharel em Teologia pelo Seminário Presbiteriano Brasil Central, Goiânia/GO (1999); licenciado em Pedagogia pela Universidade Federal de Goiás (1999); especialista em Metodologia do Ensino Superior pela Universidade Estadual de Goiás (2001); especialista em Gestão Empresarial pela Faculdade Serra da Mesa - FASEM, Uruaçu/GO (2010); especialista em Educação Didática: EAD e Novas Tecnologias, pela Faculdade Educacional da Lapa - Fael (2011). Mestre em Educação pelo Programa de Pós- Graduação em Educação da Faculdade de Educação (PPGE-FE) da UFG, na linha de pesquisa Educação, Trabalho e Movimentos Sociais. Doutorando em Educação pelo PPGE-FE/UFG. Atualmente, é professor do ensino básico, técnico e tecnológico do Instituto Federal de Goiás, campus Uruaçu.

E-mail: rodrigo123amorim@gmail.com 